Article

\title{
Structure Determination of Novel Oxidation Products from Epicatechin: Thearubigin-Like Molecules
}

\author{
Kazuhiro Uchida, Kazuki Ogawa and Emiko Yanase * \\ Faculty of Applied Biological Sciences, Gifu University, 1-1 Yanagido, Gifu 501-1193, Japan; \\ u8121006@edu.gifu-u.ac.jp (K.U.); t8121010@edu.gifu-u.ac.jp (K.O.) \\ * Correspondence: e-yanase@gifu-u.ac.jp; Tel.: +81-58-234-2914 \\ Academic Editor: Derek J. McPhee \\ Received: 29 January 2016 ; Accepted: 23 February 2016 ; Published: 26 February 2016
}

\begin{abstract}
Following the oxidation of epicatechin (EC), three novel compounds and two known compounds were isolated. The chemical structures of these oxidation products were determined by mass spectrometry (MS) and various nuclear magnetic resonance (NMR) experiments, and the A-ring-B-ring linkage that is characteristic of catechin was found in each molecule. Three compounds showed similar ultraviolet-visible (UV-Vis) spectra to EC, whereas two compounds showed different spectral absorption in the region between 300 and $500 \mathrm{~nm}$. A similar spectrum was obtained for the thearubigin fraction prepared from a black tea infusion. This result suggests that the condensation reaction between the A-ring and B-ring is more important than reaction between B-rings for thearubigin formation.
\end{abstract}

Keywords: epicatechin; oxidation; thearubigin; theaflavine; polymeric polyphenol; black tea

\section{Introduction}

Black tea is a globally popular beverage that has attracted attention because of its health benefits, including antioxidative and anticarcinogenic activities. Tea can be classified by differences in processing methods, for example, black tea is a fermented tea. The term "fermented" refers to natural browning reactions induced by oxidative enzymes of the fresh tea leaves. Catechins are one of the components in tea that are drastically changed in this process, and dimers and polymers are generated. The polymer found in black tea is called thearubigin. The name thearubigin was given to an ill-defined group of substances by Roberts in 1962. Thearubigin has a rust-brown color and high water solubility. Many researchers have studied the chemical structure of thearubigin, and the average molecular weight was estimated to be approximately 5000 to 30,000 . Thearubigin constitutes approximately $10 \%-20 \%$ of the dry weight of black tea leaves; however, detailed chemical studies have thus far been limited because the numerous components found in the extract leads to a complicated mixture, which makes preparative scale isolation difficult [1-4].

Theaflavins [5-8] are one of the pigments in black tea that have a familiar bright red tone and various bioactivities $[9,10]$. In the synthesis of theaflavin from epicatechin $(\mathbf{1}, \mathrm{EC})$ and epigallocatechin, the synthetic yield increased when an excessive amount of $\mathbf{1}$ was used for this reaction. However, the recovery of $\mathbf{1}$ was low after the reaction. This result suggested that another reaction could occur between catechol-type catechins. We consider reactions between catechol-type catechins likely to occur during the fermentation process of black tea and thus be involved in thearubigin generation. Therefore, it is important to clarify the chemical structures of the byproducts from the synthesis of theaflavin.

In this study, to increase knowledge of the chemical structure of thearubigin, we investigated the oxidation reaction of $\mathbf{1}$. Structure determination of the three novel and two known compounds 
isolated showed the importance of condensation reactions between catechin A- and B-rings for thearubigin formation.

\section{Results and Discussion}

Oxidation of 1 was performed using copper chloride, and the reaction mixture was analyzed using high-performance liquid chromatography with ultraviolet detection (HPLC-UV) (Figure 1). As a result, $\mathbf{1}$ and five unknown peaks, which were determined to be two dimers (peak c and d) and three trimers (peak a, b and e), were observed. The yield of each peak depended on the reaction conditions, oxidizing agent, reagent equivalents, reaction time, etc. For isolation and structure determination of each peak, the reaction was performed under optimum conditions for that peak. The reaction solution was extracted sequentially with ether and ethyl acetate. According to the HPLC analysis of each layer, the water layer contained peaks a and b, whereas the ethyl acetate layer contained peaks $c, d$, and e. Unreacted 1 was extracted into the ether layer. To collect peaks a and b, the water layer was loaded into a column packed with Diaion HP20SS particles and eluted with $\mathrm{MeOH}$. Each peak was separated using preparative HPLC and characterized using spectroscopic techniques, including 1D and 2D nuclear magnetic resonance (NMR) and mass spectrometry.

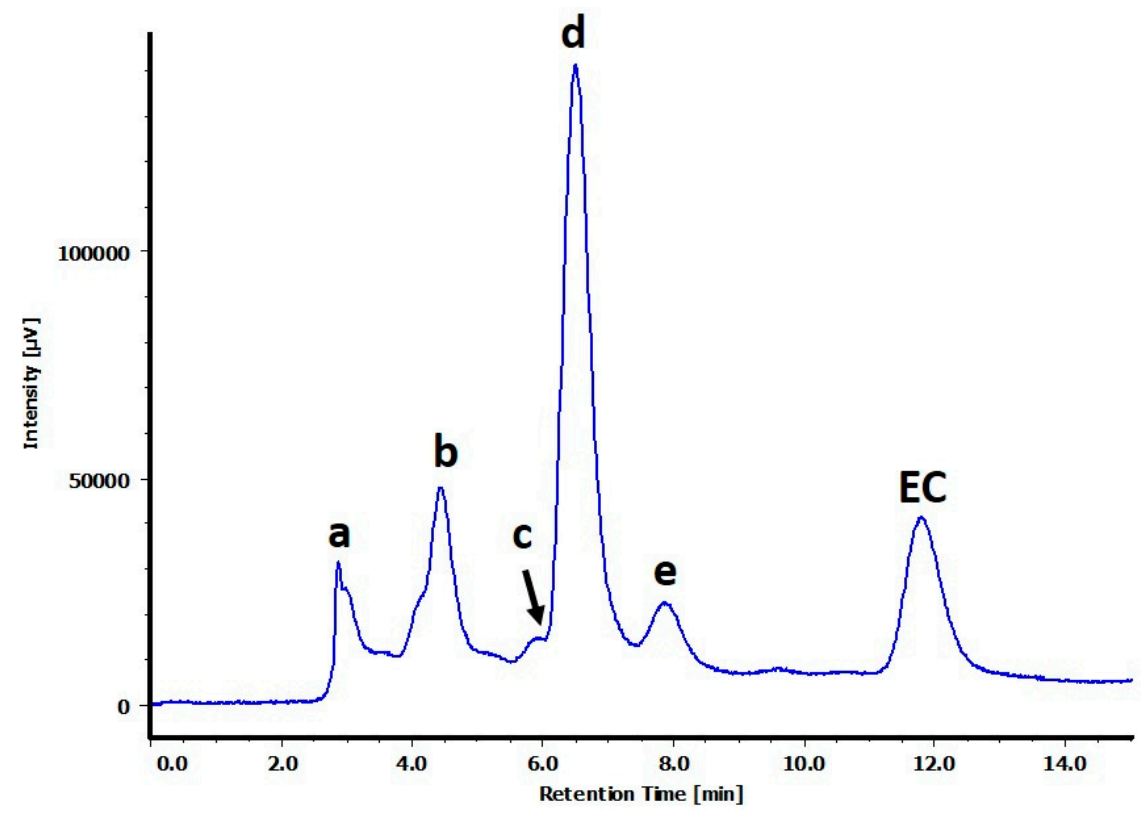

Figure 1. HPLC chromatogram of the reaction mixture obtained following oxidation of epicatechin (EC) (monitored at $280 \mathrm{~nm}$ ). Peaks were shown as a-d. a: dehydrotricatechin $\mathrm{B}_{2}$ (5), b: dehydrotricatechin $\mathrm{B}_{1}$ (6), c: epicatechin-6',6-dimer (2), d: epicatechin-6',8-dimer (3), e: dehydrotricatechin A (4), EC: epicatechin (1).

\subsection{Structure Determination for Peaks $c$ and $d$}

Negative mode electrospray ionization mass spectrometry (ESIMS) measurements of peaks c and $\mathrm{d}$ both showed a pseudo-molecular ion peak at $m / z 577\left([\mathrm{M}-\mathrm{H}]^{-}\right)$, suggesting that these compounds are dimers of $\mathbf{1}$. The ${ }^{1} \mathrm{H}-\mathrm{NMR}$ spectra of peaks $\mathbf{c}$ and $\mathbf{d}$ were similar and indicated the presence of two EC units that had lost one aromatic proton from both the A-ring and B-ring. Furthermore, the ${ }^{1} \mathrm{H}$ - and ${ }^{13} \mathrm{C}-\mathrm{NMR}$ spectral signals were assigned using correlation spectroscopy (COSY), heteronuclear multiple quantum coherence (HMQC), and heteronuclear multiple-bond correlation (HMBC). As a result, the chemical structure of peak $\mathrm{c}$ was deduced to be the EC dimer with a connection between the 6-position of the A-ring in one molecule and the $2^{\prime}$-position of the B-ring in the other (compound 2). On the other hand, peak $\mathrm{d}$ was found to be the EC dimer with a connection between the 8-position of the A-ring and 
the $2^{\prime}$-position of the B-ring (compound 3), as shown in Figure 2. Compounds 2 and 3 have with been previously reported as the products of radical oxidation of $\mathbf{1}$, and the spectral data were in agreement published data [11]. As a result, compounds 2 and 3 were identified as epicatechin- $6{ }^{\prime}, 6$-dimer and epicatechin-6', $6^{\prime}$-dimer.<smiles>Oc1cc(O)c2c(c1)O[C@H](c1ccc(O)c(O)c1)[C@H](O)C2</smiles>

1

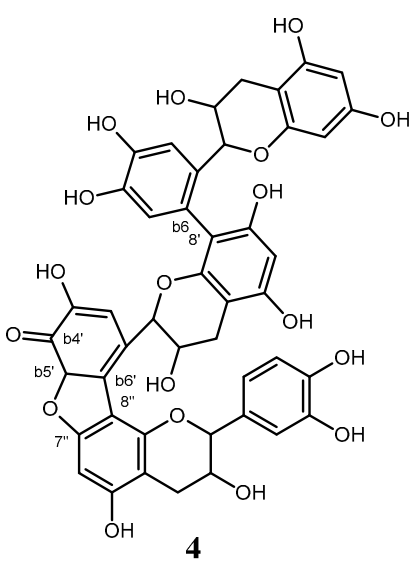<smiles>Oc1cc(O)c2c(c1)OC(c1cc(O)c(O)cc1-c1c(O)cc3c(c1O)CC(O)C(c1ccc(O)c(O)c1)O3)C(O)C2</smiles>

2<smiles></smiles>

5<smiles>Oc1cc(O)c2c(c1)OC(c1cc(O)c(O)cc1-c1c(O)cc(O)c3c1OC(c1ccc(O)c(O)c1)C(O)C3)C(O)C2</smiles>

3

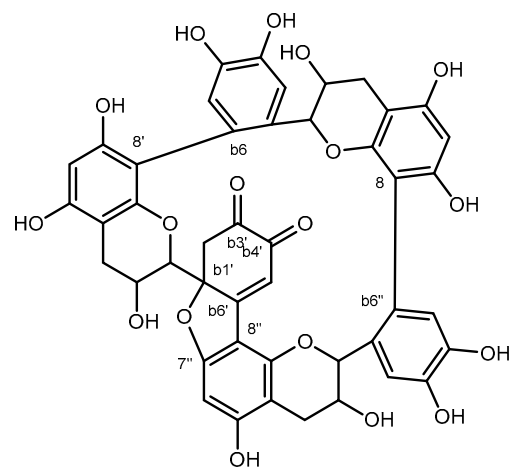

6

Figure 2. Chemical structures of compounds 1-6.

\subsection{Structure Determination for Peak e}

Negative mode ESIMS measurements of peak e showed a pseudo-molecular ion peak at $\mathrm{m} / \mathrm{z}$ $863\left([\mathrm{M}-\mathrm{H}]^{-}\right)$, suggesting that this compound is a trimer of $\mathbf{1}$. The mass number was 2 Da smaller than the expected molecular weight calculated for a simple EC trimer with connections between EC units similar to those in dimers 2 and 3. This result indicated that the EC units were connected via a double bond or three linkages. The ${ }^{1} \mathrm{H}-\mathrm{NMR}$ spectrum showed the presence of three pairs of signals corresponding to the 2-positions and 3-positions of the C-rings, indicating that these rings were unmodified. HMQC and HMBC data showed that the linkages of the three catechin units were between the A- and B-rings. In the ${ }^{13} \mathrm{C}$-NMR spectrum, a characteristic signal at $190 \mathrm{ppm}$ indicated the presence of a ketone. This signal was correlated with methine (3.1 ppm), which, in HMBC, was correlated with the 7- and 8-positions of an A-ring and 1'-position of a B-ring, as shown in Figure 3 . These results indicated the presence of a ketone in a B-ring that had lost aromaticity and the formation of a five-membered ring via an ether bond between the A-ring of one EC unit and the B-ring of another unit. Furthermore, the ${ }^{1} \mathrm{H}$ - and ${ }^{13} \mathrm{C}-\mathrm{NMR}$ spectral signals were assigned based on COSY, HMQC, and HMBC (Figure 3). As a result, the structure of compound 4 was determined, as shown in Figure 2. We have named 4 dehydrotricatechin A. 


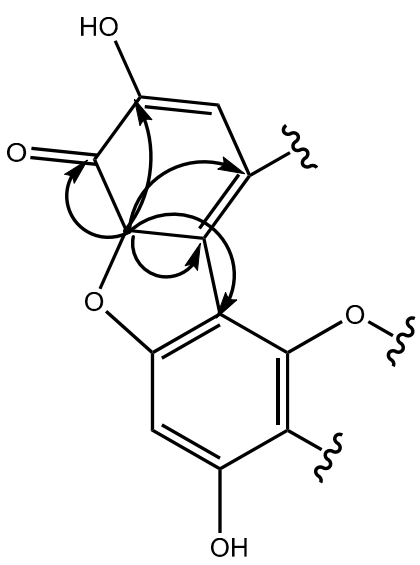

4

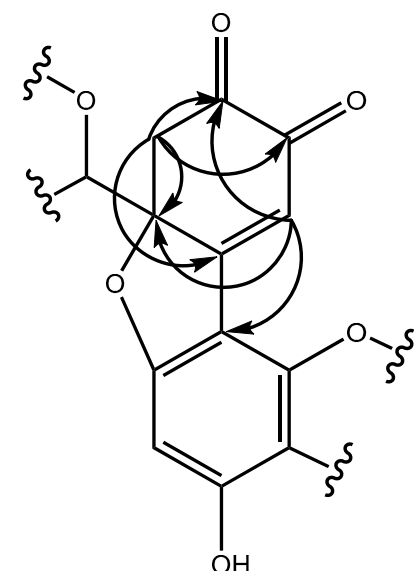

6

Figure 3. HMBC correlations for compounds 4 and 6 .

\subsection{Structure Determination for Peaks $a$ and $b$}

Peak a was analyzed by negative mode ESIMS. The appearance of an $[\mathrm{M}-\mathrm{H}]^{-}$ion peak at $m / z 863$, which was the same as that observed for compound 4 , suggested that compound 5 is a trimer of $\mathbf{1}$ with three linkages. In contrast to those of 4 , the ${ }^{1} \mathrm{H}$ - and ${ }^{13} \mathrm{C}-\mathrm{NMR}$ spectra of $\mathbf{5}$ were simple and similar to those of monomeric $\mathbf{1}$, except for the lack of one aromatic proton from each A-ring and B-ring. Although compound 5 was clearly different from 1, we could not obtain further spectral evidence to confirm the complete structure of peak $\mathbf{a}$.

Peak $\mathbf{b}$ showed $\mathbf{a}[\mathrm{M}-\mathrm{H}]^{-}$peak at $m / z 861$ in negative mode ESIMS, indicating that this compound is another EC trimer. Three sets of signals arising from the 2-positions and 3-positions of the C-rings were observed in the ${ }^{1} \mathrm{H}-\mathrm{NMR}$ spectrum, indicating the presence of unmodified C-rings. The HMBC correlations observed between A-ring protons and B-ring carbons indicated that the EC units are connected between the A- and B-rings. The ${ }^{13} \mathrm{C}-\mathrm{NMR}$ signals at 190 and $180 \mathrm{ppm}$ indicated the presence of two ketone groups. Based on HMQC, the correlations between these ketones and protons with signals at 4.47 and $2.81 \mathrm{ppm}$ indicated that the ketones are geminal. Furthermore, the HMBC correlations of these ketones indicated a chemical skeleton that could be attributed to the 1,4-conjugated addition of the phenolic $\mathrm{OH}$ in the A-ring to $\mathrm{O}$-quinone, resulting in a loss of aromaticity. All remaining signals in the ${ }^{1} \mathrm{H}$ - and ${ }^{13} \mathrm{C}-\mathrm{NMR}$ spectra were assigned based on COSY, HMQC, and HMBC (Figure 3). As a result, the structure of compound $\mathbf{6}$ was determined, as shown in Figure 2. We have named 6 dehydrotricatechin $\mathrm{B}_{1}$.

Compound 6 was unstable in $\mathrm{CD}_{3} \mathrm{OD}$ and was converted to another compound with an NMR spectrum consistent with that of peak a. On the other hand, the $\mathrm{CD}_{3} \mathrm{OD}$ solution of peak a did not show conversion to compound $\mathbf{6}$. This result indicated that compound $\mathbf{6}$ was irreversibly converted to compound 5. Based on this observation and the NMR and ESIMS data described above, the chemical structure of compound 5 was proposed, as shown in Figure 2. We have named 5 dehydrotricatechin $B_{2}$.

\subsection{Formation Mechanisms of Compounds 2-6}

On the basis of the chemical structures of compounds 2-6, we proposed mechanisms for the formation of these compounds from $\mathbf{1}$, as shown in Figure 4 . When $\mathbf{1}$ is treated with an oxidizing agent, the catechol-type B-ring is oxidized to form $O$-quinone. The nucleophilic addition of the B-rings of epigallocatechin and epigallocatechin gallate to $O$-quinone occurs because of their high electron density, and eventually leads to the formation of theaflavins [11]. On the other hand, the nucleophilic addition of $\mathbf{1}$ to $\mathrm{O}$-quinone occurs at the A-ring because of its higher electron density compared with that of the B-ring. Nucleophilic addition at the $\mathrm{C} 8$ or $\mathrm{C} 6$ position results in the formation of dimers, such as compounds $\mathbf{2}$ and $\mathbf{3}$, or trimers, such as compound 5. Furthermore, the catechol unit of the 
resulting product can be oxidized again to $O$-quinone and converted to compound 4 by intramolecular cyclization of the C7-hydroxy group with the $\mathrm{C}^{\prime}$ position. Intramolecular cyclization can also occur with the $\mathrm{C} 1$ position to generate compound $\mathbf{6}$. Compound 4 is converted into compound 5 through a ring opening reaction caused by aromatization. This formation mechanism suggested that the polymerization of catechin results from its oxidation, and further oxidation of these products results in the formations of compounds such as $\mathbf{4}$ and $\mathbf{6}$.

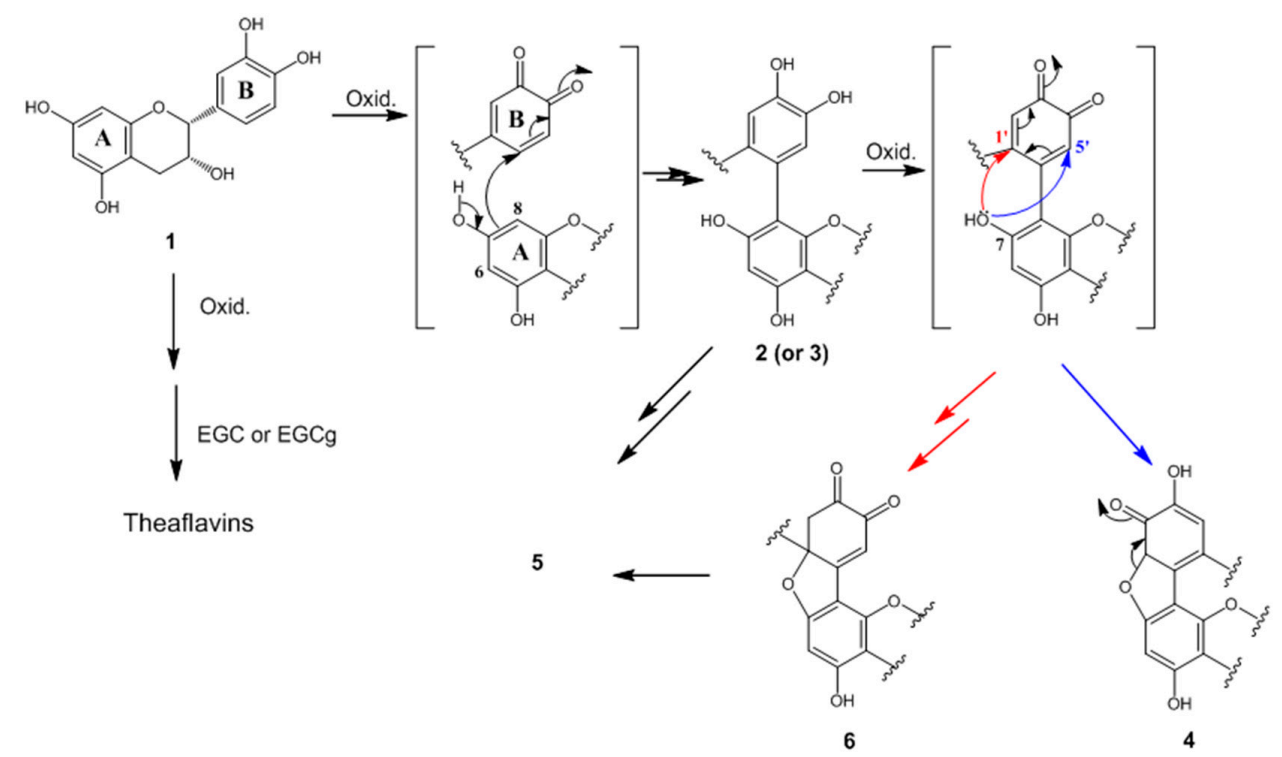

Figure 4. Formation mechanisms of compounds 2-6 from $\mathbf{1}$.

\subsection{UV-Vis Spectra}

To study the relationship between chemical structure and color, the ultraviolet-visible (UV-Vis) spectra of compounds 2-6 were obtained. Compounds 2, 3, and 5 showed similar spectra to that of 1, which has a maximum absorption wavelength at $278 \mathrm{~nm}$. On the other hand, compounds 4 and 6 showed spectral absorption in the region between 300 and $500 \mathrm{~nm}$, which was not observed in the spectrum of 1 (Figure 5). This result indicated that the formation of the new five-membered ring in compounds $\mathbf{4}$ and $\mathbf{6}$ allowed conjugation between an A-ring and B-ring, resulting in absorption in the visible range.

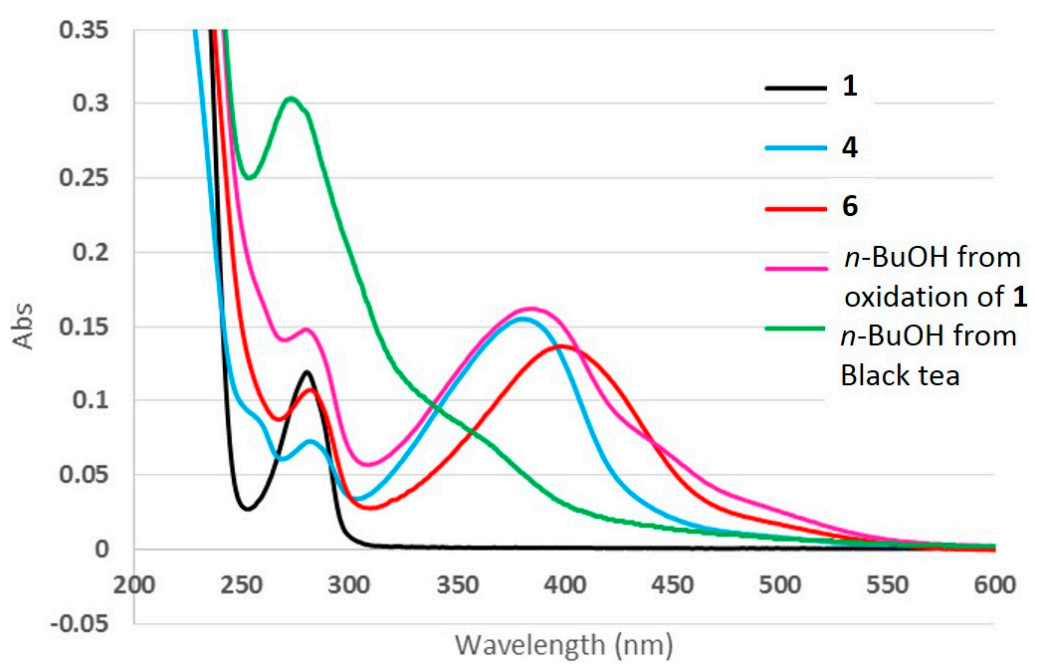

Figure 5. UV-Vis spectra of compounds 1,4 , and 6 , and the $n$ - $\mathrm{BuOH}$ extracts. 
Oxidation of 1 was performed under strong oxidation conditions using $\mathrm{K}_{3} \mathrm{Fe}(\mathrm{CN})_{6} / \mathrm{NaHCO}_{3}$, and the reaction mixture was extracted using ether, EtOAc, and $n-\mathrm{BuOH}$, in the listed order. When each extract was analyzed by HPLC, the $n-\mathrm{BuOH}$ extract produced broad overlapping peaks. In addition, line broadening was observed in the ${ }^{1} \mathrm{H}-\mathrm{NMR}$ spectrum of the $n-\mathrm{BuOH}$ extract. These results suggested that the $n$ - $\mathrm{BuOH}$ extract contained thearubigin-like polymers that were generated by the oxidation reaction. The UV-Vis spectrum of this $n-\mathrm{BuOH}$ fraction showed similar spectral features to those of compounds 4 and 6 . This result indicated that the components in the $n$ - $\mathrm{BuOH}$ fraction have chromophores with structures similar to those of compounds 4 and $\mathbf{6}$.

Thearubigins are the most abundant pigments in black tea and are formed by enzymatic oxidization of catechins during the fermentation process. These compounds are polymeric polyphenols with unresolved structures [2-4]. To obtain the UV-Vis spectrum of these compounds, the hot water extract of black tea leaves was extracted using ether, EtOAc, and $n-\mathrm{BuOH}$, in the listed order, and the $n$-BuOH extract was further fractionated into two fractions (Fr. 1 and 2) using a Toyopearl HW-40C column. The UV-Vis spectrum of Fr. 2, which had a reddish-brown color, showed a wide absorption band in the 300-500 nm region, similar to that of the $n$-BuOH extract of the oxidation mixture of 1 described above. The absorption band of the black tea extract was observed at $360 \mathrm{~nm}$, which was somewhat blue-shifted in comparison to those of compounds 4 and $\mathbf{6}$ and the $n$-BuOH extract of the oxidation mixture of $\mathbf{1}$. It is assumed that this difference is because thearubigins from black tea are a complex mixture that contains some products formed by conjugation between catechin and other components in addition to polymers derived only from catechins.

\section{Experimental Section}

\subsection{Materials}

EC was purchased from Sigma-Aldrich Co. LLC (St. Louis, MO, USA). Copper(II) chloride dihydrate and potassium hexacyanoferrate(III) were purchased from Nacalai Tesque Co. (Kyoto, Japan). Sodium hydrogen carbonate was purchased from Kishida Chemical Co., Ltd. (Osaka, Japan). $\mathrm{CD}_{3} \mathrm{OD}$ was purchased from Kanto Chemical Co. (Tokyo, Japan). Acetone- $d_{6}$ was purchased from Acros Organics Co. (Morris Plains, NJ, USA).

\subsection{Instrumentation}

${ }^{1} \mathrm{H}$ - and ${ }^{13} \mathrm{C}-\mathrm{NMR},{ }^{1} \mathrm{H}-\mathrm{COSY}, \mathrm{HMQC}$, and HMBC spectra were recorded on a JEOL ECA 600 spectrometer (JEOL, Tokyo, Japan) at $600 \mathrm{MHz}$ for ${ }^{1} \mathrm{H}$ and a Bruker Biospin AVANCE III 800 spectrometer (Bruker, Germany) at $200 \mathrm{MHz}$ for ${ }^{13} \mathrm{C}$. ESIMS spectra were measured on a JMS-T100TD mass spectrometer (JEOL). Column chromatography was carried out using Diaion HP20SS (Mitsubishi Chemical Co., Tokyo, Japan) and Toyopearl HW-40C (Tosho Co., Tokyo, Japan). HPLC was performed with a JASCO PU-2089 or JASCO PU-887 system using a reverse-phase HPLC column (NB-ODS-9 4.6 mm I.D. × 250 mm, NX-ODS-9 10 mm I.D. × 250 mm, Nagara Science Co., Gifu, Japan) and JASCO MD-2010 or JASCO 875-UV detectors (JASCO Co., Tokyo, Japan). UV-Vis spectra were recorded on a Perkin Elmer Lambda 950 UV/VIS/NIR spectrometer (Kanagawa, Japan).

\subsection{Synthesis of $\mathbf{a}$ and $\mathbf{b}$}

An aqueous solution of $\mathrm{EC}(0.2 \mathrm{mmol})$ and $\mathrm{CuCl}_{2} \cdot 2 \mathrm{H}_{2} \mathrm{O}(1.0 \mathrm{mmol})$ in $\mathrm{H}_{2} \mathrm{O}$ was vigorously stirred at room temperature for $3 \mathrm{~h}$. The reaction mixture was extracted with $\mathrm{Et}_{2} \mathrm{O}$. The water layer was extracted with EtOAc. The water layer was concentrated until EtOAc had been removed and the resulting solution was subjected to column chromatography using a HP20SS resin. The column was eluted with $\mathrm{MeOH}$ after washing with water to remove $\mathrm{CuCl}_{2}$, and the resulting solution was separated by reverse-phase HPLC (25\% MeOH, $0.5 \% \mathrm{HCOOH}$ in $\left.\mathrm{H}_{2} \mathrm{O}\right)$ to afford $\mathbf{a}$ and $\mathbf{b}$.

Compound a (5): ESIMS, m/z: $863\left([\mathrm{M}-\mathrm{H}]^{-}\right) .{ }^{1} \mathrm{H}-\mathrm{NMR}\left(600 \mathrm{MHz}, \mathrm{CD}_{3} \mathrm{OD}\right) \delta: 6.74(1 \mathrm{H}, \mathrm{s}, \mathrm{H}-\mathrm{b} 2)$, $6.64(1 \mathrm{H}, \mathrm{s}, \mathrm{H}-\mathrm{b} 5), 6.01$ (1H, s, H-6), 4.41 (1H, s, H-2), 3.90 (1H, m, H-3), $2.56(1 \mathrm{H}, \mathrm{dd}, J=16.5$ and $4.1 \mathrm{~Hz}$, 
H-4). ${ }^{13}$ C-NMR (200 MHz, CD OD) 8: 155.6 (C-5), 153.3 (C-7), 152.7 (C-8a), 143.7 (C-b3), 143.2 (C-b4), 130.7 (C-b1), 123.6 (C-b6), 117.8 (C-b5), 115.0 (C-b2), 106.5 (C-8), 98.2 (C-4a), 94.2 (C-6), 76.2 (C-2), $63.8(\mathrm{C}-3), 27.3(\mathrm{C}-4)$.

Compound b (6): ESIMS, $m / z: 861\left([\mathrm{M}-\mathrm{H}]^{-}\right) .{ }^{1} \mathrm{H}-\mathrm{NMR}\left(600 \mathrm{MHz}\right.$, acetone- $\left.\mathrm{d}_{6}\right) \delta: 7.90(1 \mathrm{H}, \mathrm{s}$, H-b2' $\left.{ }^{\prime \prime}\right), 6.81\left(1 \mathrm{H}, \mathrm{s}, \mathrm{H}-\mathrm{b} 5^{\prime \prime}\right), 6.80(1 \mathrm{H}, \mathrm{s}, \mathrm{H}-\mathrm{b} 5), 6.27$ (1H, s, H-b2), $6.14\left(1 \mathrm{H}, \mathrm{s}, \mathrm{H}-\mathrm{b} 5^{\prime}\right), 6.10\left(1 \mathrm{H}, \mathrm{s}, \mathrm{H}-6^{\prime}\right)$, $6.07\left(1 \mathrm{H}, \mathrm{s}, \mathrm{H}-6^{\prime \prime}\right), 6.02(1 \mathrm{H}, \mathrm{s}, \mathrm{H}-6), 4.73\left(1 \mathrm{H}, \mathrm{s}, \mathrm{H}-2^{\prime \prime}\right), 4.56\left(1 \mathrm{H}, \mathrm{brs}, \mathrm{H}-3^{\prime}\right), 4.47(1 \mathrm{H}, \mathrm{d}, J=14.4 \mathrm{~Hz}$, H-b2'), $4.45\left(1 \mathrm{H}\right.$, brs, H-3"'), $4.36(1 \mathrm{H}, \mathrm{s}, \mathrm{H}-2), 3.91(1 \mathrm{H}, \mathrm{s}, \mathrm{H}-3), 3.52\left(1 \mathrm{H}, \mathrm{s}, \mathrm{H}-2^{\prime}\right), 2.9\left(1 \mathrm{H}, \mathrm{H}-4^{\prime}\right.$; this peak could not be observed in ${ }^{1} \mathrm{H}-\mathrm{NMR}$ due to overlap with the $\mathrm{H}_{2} \mathrm{O}$ signal), $2.84(2 \mathrm{H}, \mathrm{m}, \mathrm{H}-\mathrm{b} 2$ ', $\left.4^{\prime \prime}\right), 2.68\left(1 \mathrm{H}, \mathrm{dd}, J=12.6\right.$ and $\left.3.0 \mathrm{~Hz}, \mathrm{H}-4^{\prime \prime}\right), 2.59(1 \mathrm{H}, \mathrm{d}, J=12.6 \mathrm{~Hz}, \mathrm{H}-4), 2.17(1 \mathrm{H}, \mathrm{dd}, J=12.3$ and $3.0 \mathrm{~Hz}, \mathrm{H}-4), 2.1\left(1 \mathrm{H}, \mathrm{H}-4^{\prime}\right.$, this peak could not be observed in ${ }^{1} \mathrm{H}-\mathrm{NMR}$ due to overlap with the acetone signal). ${ }^{13} \mathrm{C}-\mathrm{NMR}\left(200 \mathrm{MHz}\right.$, acetone- $\left.d_{6}\right) \delta: 190.8\left(\mathrm{C}-\mathrm{b} 3^{\prime}\right), 177.4\left(\mathrm{C}-\mathrm{b} 4^{\prime}\right), 163.8\left(\mathrm{C}-7^{\prime \prime}\right)$, $162.9\left(\mathrm{C}-8 \mathrm{a}^{\prime \prime}\right), 159.7\left(\mathrm{C}-\mathrm{b} 6^{\prime}\right), 156.1\left(\mathrm{C}-5^{\prime}\right), 156.0\left(\mathrm{C}-5^{\prime \prime}\right), 155.4(\mathrm{C}-5), 154.2\left(\mathrm{C}-7^{\prime}\right), 153.9(\mathrm{C}-8 \mathrm{a}), 153.4(\mathrm{C}-7)$, $150.6\left(\mathrm{C}-8 \mathrm{a}^{\prime}\right), 145.6$ (C-b4), $144.0\left(\mathrm{C}-\mathrm{b} 4^{\prime \prime}\right), 143.8$ (C-b3), 131.4 (C-b1), 130.0 (C-b6), 127.3 (C-b1'), 119.7 (C-b6" $), 119.5$ (C-b2), 118.3 (C-b5'), 117.9 (C-b5'), 116.3 (C-b2' $), 114.7$ (C-b5), 107.1 (C-8), $106.9\left(\mathrm{C}-8^{\prime}\right), 103.4\left(\mathrm{C}-8^{\prime \prime}\right), 102.3\left(\mathrm{C}-4 \mathrm{a}^{\prime \prime}\right), 99.0\left(\mathrm{C}-4 \mathrm{a}^{\prime}\right), 98.9(\mathrm{C}-4 \mathrm{a}), 95.7\left(\mathrm{C}-6^{\prime}\right), 94.0(\mathrm{C}-6), 90.6\left(\mathrm{C}-6^{\prime \prime}\right)$, $90.0\left(\mathrm{C}-\mathrm{b} 1^{\prime}\right), 77.2\left(\mathrm{C}-2^{\prime}\right), 76.8\left(\mathrm{C}-2^{\prime \prime}\right), 76.7(\mathrm{C}-2), 64.6\left(\mathrm{C}-3^{\prime \prime}\right), 63.0(\mathrm{C}-3), 61.6\left(\mathrm{C}-3^{\prime}\right), 47.2\left(\mathrm{C}-2^{\prime}\right), 31.1\left(\mathrm{C}-4^{\prime \prime}\right)$, $29.4\left(\mathrm{C}-4^{\prime}\right), 27.7(\mathrm{C}-4)$.

\subsection{Synthesis of $\mathbf{c}$ and $\mathbf{d}$}

An aqueous solution of EC $(0.2 \mathrm{mmol})$ and $\mathrm{CuCl}_{2} \cdot 2 \mathrm{H}_{2} \mathrm{O}(0.4 \mathrm{mmol})$ in $\mathrm{H}_{2} \mathrm{O}$ was vigorously stirred at room temperature for $1 \mathrm{~h}$. The reaction mixture was extracted with $\mathrm{Et}_{2} \mathrm{O}$. The water layer was extracted with EtOAc. The EtOAc layer was concentrated, and then separated by reverse-phase HPLC $\left(25 \% \mathrm{MeOH}, 0.5 \% \mathrm{HCOOH}\right.$ in $\mathrm{H}_{2} \mathrm{O}$ ) to afford $\mathbf{c}$ and $\mathbf{d}$.

\subsection{Synthesis of $\mathbf{e}$}

A solution of $\mathrm{EC}$ and $\mathrm{K}_{3} \mathrm{Fe}(\mathrm{CN})_{6}$ in $\mathrm{NaHCO}_{3}$ aq. was vigorously stirred at $0{ }^{\circ} \mathrm{C}$ for $6 \mathrm{~min}$. The mixture was sequentially extracted with $\mathrm{Et}_{2} \mathrm{O}, \mathrm{EtOAc}$, and $n-\mathrm{BuOH}$, in the listed order. The EtOAc layer was concentrated, and then separated by reverse-phase HPLC $(25 \% \mathrm{MeOH}, 0.5 \% \mathrm{HCOOH}$ in $\mathrm{H}_{2} \mathrm{O}$ ) to afford $\mathbf{e}$. The $n-\mathrm{BuOH}$ fraction was concentrated to afford a residue.

Compound e (4): ESIMS, $m / z: 863\left([\mathrm{M}-\mathrm{H}]^{-}\right) \cdot{ }^{1} \mathrm{H}-\mathrm{NMR}\left(600 \mathrm{MHz}, \mathrm{CD}_{3} \mathrm{OD}\right) \delta: 7.04(1 \mathrm{H}, \mathrm{d}, J=1.4 \mathrm{~Hz}$, H-b2" $\left.{ }^{\prime \prime}\right), 6.92(1 \mathrm{H}, \mathrm{s}, \mathrm{H}-\mathrm{b} 2), 6.90\left(1 \mathrm{H}, \mathrm{d}, J=6.0 \mathrm{~Hz}, \mathrm{H}-\mathrm{b} 6^{\prime \prime}\right), 6.81\left(1 \mathrm{H}, \mathrm{d}, J=8.2 \mathrm{~Hz}, \mathrm{H}-\mathrm{b} 5^{\prime \prime}\right), 6.41(1 \mathrm{H}$, s, H-b5), $6.15\left(1 \mathrm{H}, \mathrm{s}, \mathrm{H}-\mathrm{b} 2^{\prime}\right), 6.13(1 \mathrm{H}, \mathrm{d}, J=2.1 \mathrm{~Hz}, \mathrm{H}-8), 6.07\left(1 \mathrm{H}, \mathrm{s}, \mathrm{H}-6^{\prime \prime}\right), 6.03\left(1 \mathrm{H}, \mathrm{s}, \mathrm{H}-6^{\prime}\right)$, $5.95(1 \mathrm{H}, \mathrm{d}, J=2.0 \mathrm{~Hz}, \mathrm{H}-6), 5.24\left(1 \mathrm{H}, \mathrm{s}, \mathrm{H}-2^{\prime \prime}\right), 5.00\left(1 \mathrm{H}, \mathrm{d}, J=8.2 \mathrm{~Hz}, \mathrm{H}-3^{\prime}\right), 4.38(1 \mathrm{H}, \mathrm{s}, \mathrm{H}-2)$, $4.26\left(1 \mathrm{H}, \mathrm{brs}, \mathrm{H}-3^{\prime \prime}\right), 4.16\left(1 \mathrm{H}, \mathrm{d}, J=2.7 \mathrm{~Hz}, \mathrm{H}-2^{\prime}\right), 3.71(1 \mathrm{H}, \mathrm{brs}, \mathrm{H}-3), 3.26(1 \mathrm{H}, \mathrm{dd}, J=12.6$ and $\left.3.0 \mathrm{~Hz}, \mathrm{H}-4^{\prime \prime}\right), 3.1\left(2 \mathrm{H}, \mathrm{m}, \mathrm{H}-\mathrm{b} 5^{\prime}, 4^{\prime}\right), 2.84\left(1 \mathrm{H}, \mathrm{d}, J=12.0 \mathrm{~Hz}, \mathrm{H}-4^{\prime \prime}\right), 2.60(1 \mathrm{H}, \mathrm{d}, J=13.8 \mathrm{~Hz}$, $\left.\mathrm{H}-4^{\prime}\right), 2.57(1 \mathrm{H}, \mathrm{d}, J=12.6 \mathrm{~Hz}, \mathrm{H}-4), 2.31(1 \mathrm{H}, \mathrm{dd}, J=12.6$ and $3.6 \mathrm{~Hz}, \mathrm{H}-4) .{ }^{13} \mathrm{C}-\mathrm{NMR}(200 \mathrm{MHz}$,

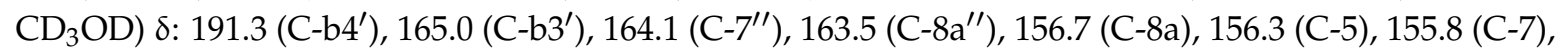
$154.8\left(\mathrm{C}-5^{\prime}, 5^{\prime \prime}\right), 153.6\left(\mathrm{C}-7^{\prime}\right), 151.2\left(\mathrm{C}-8 \mathrm{a}^{\prime}\right), 144.4\left(\mathrm{C}-\mathrm{b} 4^{\prime \prime}\right), 144.3\left(\mathrm{C}-\mathrm{b} 3^{\prime \prime}\right), 143.2(\mathrm{C}-\mathrm{b} 4, \mathrm{C}-\mathrm{b} 3), 130.8\left(\mathrm{C}-\mathrm{b} 1^{\prime \prime}\right)$, 129.6 (C-b1), 122.1 (C-b6), 118.1 (C-b6"), 117.7 (C-b5), 114.7 (C-b5"'), 114.1 (C-b2), 113.9 (C-b2' '), $108.5\left(\mathrm{C}-\mathrm{b} 22^{\prime}\right), 107.3\left(\mathrm{C}-8^{\prime}\right), 104.5\left(\mathrm{C}-8^{\prime \prime}\right), 101.5\left(\mathrm{C}-4 \mathrm{a}^{\prime \prime}\right), 98.7\left(\mathrm{C}-4 \mathrm{a}^{\prime}\right), 98.6(\mathrm{C}-4 \mathrm{a}), 95.6\left(\mathrm{C}-6^{\prime}\right), 95.2(\mathrm{C}-8)$, 94.6 (C-6), $93.8\left(\mathrm{C}-\mathrm{b} 6^{\prime}\right), 90.7\left(\mathrm{C}-6^{\prime \prime}\right), 89.9\left(\mathrm{C}-\mathrm{b} 1^{\prime}\right), 78.7\left(\mathrm{C}-2^{\prime}\right), 78.6\left(\mathrm{C}-2^{\prime \prime}\right), 76.1(\mathrm{C}-2), 68.1\left(\mathrm{C}-3^{\prime}\right), 65.4\left(\mathrm{C}-3^{\prime \prime}\right)$, $64.1(\mathrm{C}-3), 39.0\left(\mathrm{C}-\mathrm{b5} 5^{\prime}\right), 27.7(\mathrm{C}-4), 27.5\left(\mathrm{C}-4^{\prime \prime}\right), 23.0\left(\mathrm{C}-4^{\prime}\right)$.

\subsection{Extraction of Black Tea}

Black tea leaves $(1.8 \mathrm{~g})$ were refluxed in water at $120^{\circ} \mathrm{C}$ for $30 \mathrm{~min}$. After cooling, the solution was extracted sequentially with $\mathrm{Et}_{2} \mathrm{O}, \mathrm{EtOAc}$, and $n-\mathrm{BuOH}$, in the listed order. The $n$ - $\mathrm{BuOH}$ extract was concentrated under reduced pressure to afford a residue. The $n$ - $\mathrm{BuOH}$ extract was further fractionated using a Toyopearl HW-40C column ( $40 \%$ acetone, $8 \mathrm{M}$ urea in $0.1 \mathrm{M} \mathrm{HCl}$ aq.) to afford Fr. 1, which had a light yellowish-brown color, and Fr. 2, which had a reddish-brown color. 


\subsection{UV-Vis Spectra}

Each sample was dissolved in methanol at a concentration of $0.01 \mathrm{mg} / \mathrm{mL}$. The spectrum of each sample was collected in the spectral range between 200 and $800 \mathrm{~nm}$ with a spectral resolution of $1 \mathrm{~nm}$. The spectra were recorded against the corresponding solvent as a baseline.

\section{Conclusions}

In conclusion, we investigated the oxidation reaction of $\mathbf{1}$ to increase knowledge of the chemical structure and formation mechanism of thearubigin. We determined the chemical structures of three novel trimers (compounds 4-6) and two known dimers (compounds 2 and 3). Furthermore, the UV-Vis spectrum of the black tea extract indicated that the chemical structures of thearubigins contain skeletons that are cyclized after the formation of linkages between A- and B-rings, as observed in compounds $\mathbf{4}$ and $\mathbf{6}$. Oxidative condensation between the B-rings of catechins has been considered the formation mechanism of thearubigins. However, this result suggests that the condensation reaction between A- and B-rings is another important mechanism for thearubigin formation. We consider this result important for resolving the chemical structures of thearubigins, and further studies are now in progress.

Acknowledgments: This work was supported by a JSPS KAKENHI Grant (Number 15K07427), by the Toyo Institute of Food Technology, and by Nagara Science Co., Ltd.

Author Contributions: E.Y. conceived and designed the experiments; K.U. and K.O. performed the experiments and contributed to data collection. E.Y. and K.U. wrote the paper.

Conflicts of Interest: The authors declare no conflict of interest.

\section{Abbreviations}

The following abbreviations are used in this manuscript:

EC Epicatechin

HPLC High-performance liquid chromatography

ESIMS Electrospray ionization mass spectrometry

NMR Nuclear magnetic resonance

COSY Correlation spectroscopy

HMQC Heteronuclear multiple quantum coherence

HMBC Heteronuclear multiple-bond correlation

\section{References}

1. Roberts, E.A.H. Economic importance of flavonoid substances: Tea fermentation. In The Chemistry of Flavonoid Compounds; Geissman, T.A., Ed.; Pergamon Press: Oxford, UK, 1962; pp. 468-512.

2. Haslam, E. Thoughts on thearubigins. Phytochemistry 2003, 64, 61-73. [CrossRef]

3. Tanaka, T.; Kouno, I. Oxidation of tea catechins: Chemical structures and reaction mechanism. Food Sci. Technol. Res. 2003, 9, 128-133. [CrossRef]

4. Yassin, G.H.; Koek, J.H.; Kuhnert, N. Model system-based mechanistic studies of black tea thearubigin formation. Food Chem. 2015, 180, 272-279. [CrossRef] [PubMed]

5. Takino, Y.; Imagawa, H.; Horikawa, H.; Tanaka, A. Studies on the mechanism of the oxidation of tea leaf catechins: Part III. Formation of a reddish orange pigment and its spectral relationship to some benzotropolone derivatives. Agric. Biol. Chem. 1964, 28, 64-71. [CrossRef]

6. Brown, A.G.; Falshaw, C.P.; Haslam, E.; Holmes, A.; Ollis, W.D. The constitution of theaflavin. Tetrahedron Lett. 1966, 7, 1193-1204. [CrossRef]

7. Collier, P.D.; Bryce, T.; Mallows, R.; Thomas, P.E.; Frost, D.J.; Korver, O.; Wilkins, C.K. The theaflavins of black tea. Tetrahedron 1973, 29, 125-142. [CrossRef]

8. Shiraki, M.; Hara, Y.; Osawa, T.; Kumon, H.; Nakayama, T.; Kawakishi, S. Antioxidative and antimutagenic effects of theaflavins from black tea. Mutat. Res. Lett. 1994, 323, 29-34. [CrossRef] 
9. Yanase, E.; Sawaki, K.; Nakatsuka, S. The isolation of a bicyclo[3.2.1] intermediate during formation of benzotropolones, a common nucleus found in black tea pigments: Theaflavins. Synlett 2005, 2661-2663.

10. Ikeda, I.; Yamahira, T.; Kato, M.; Ishikawa, A. Black-tea polyphenols decrease micellar solubility of cholesterol in vitro and intestinal absorption of cholesterol in rats. J. Agric. Food Chem. 2010, 58, 8591-8595. [CrossRef] [PubMed]

11. Sang, S.; Cheng, X.; Stark, R.E.; Rosen, R.T.; Yang, C.S.; Ho, C.T. Chemical studies on antioxidant mechanism of tea catechins: Analysis of radical reaction products of catechin and epicatechin with 2,2-diphenyl-1-picrylhydrazyl. Bioorg. Med. Chem. 2002, 10, 2233-2237. [CrossRef]

Sample Availability: Samples of the compounds are not available from the authors.

(C) 2016 by the authors; licensee MDPI, Basel, Switzerland. This article is an open access article distributed under the terms and conditions of the Creative Commons by Attribution (CC-BY) license (http://creativecommons.org/licenses/by/4.0/). 